\title{
THE DUNKL-WILLIAMS INEQUALITY WITH $n$ ELEMENTS IN NORMED LINEAR SPACES
}

\author{
JOSIP PEČARIĆ AND RAJNA RAJIĆ
}

\begin{abstract}
In this paper we establish a generalization of the Dunkl-Williams inequality for finitely many elements in a normed linear space. As a consequence, we get some recently obtained results on the generalized triangle inequality and its reverse inequality. The case of equality for elements of a strictly convex normed linear space is also considered.
\end{abstract}

Mathematics subject classification (2000): 26D15.

Key words and phrases: triangle inequality, Dunkl-Williams inequality.

\section{REFERENCES}

[1] C. F. DunKL, K. S. Williams, A simple norm inequality, Amer. Math. Monthly, 71, (1964), 53-54.

[2] M. KATO, K. S. SAITO AND T. TAMURA, Sharp triangle inequality and its reverse in Banach spaces, Math. Ineq. Appl., 10, (2) (2007), 453-462.

[3] L. Maligranda, Simple norm inequalities, Amer. Math. Monthly, 113, (2006), 256-260.

[4] J. L. MASSERA, J. J. SCHÄFFER, Linear differential equations and functional analysis I, Ann. of Math., 67, (1958), 517-573.

[5] P. R. MERCER, The Dunkl-Williams inequality in an inner-product space, Math. Inequal. Appl., 10, (2) (2007), 447-451. 